流れの可視化 Vol.6 No.22 (1986年7月)

3 油点法による高速直射式ディーゼルエンジンの

然焼室内の空気流動の可視化

$\begin{array}{lll}\text { 三菱自工 } & \text { 金色一憲 平河内信義 } \\ \text { 三蕧重工 } & \text { 中川 洋 }\end{array}$

Visualization of Air Flov Pattern in Diesel Engine Combustion Chamber by 0 il Dot Method

by Kazunori Kanairo*, Nobuyosi Hirakouchi*, Hirosi Nakagawa**

D.I. diesel engine combustion is strongly influenced by air flow in the combustion chamber. Therefore, in order to improve diesel combustion, it is very important to realize the air flow in the chamber.

In this study, 0il Dot Method was used to visualize the air flow in the piston cavity of the combustion chamber.

It is cleared that there is an air velocity deviation in the cavity, cauesd by an air flow pattern generated during intake process, a cavity size and its position.

From the above result, combustion tuning tests were carried out by a single cylinder engine and preferably good combustion was obtained finaly.

\title{
1・はじめに
}

近年 自動車用のエンジンでは然料消費量の節減、有害な排ガスの低隇等の、然焼改善 への要求がますます強くなってきており：それには燃炕通程の洋細な解明が不可欠となっ ている。ディーゼルエンジンの然㜔を改善するには、いかに速やかに燃料と空気を混合 させ、完全に然嬅させ得るか、が重要なポイントである。それには然㚾室内の空気の流

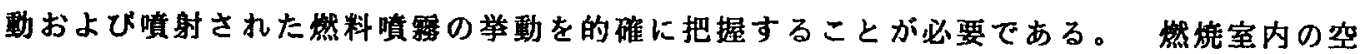

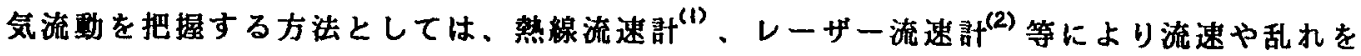

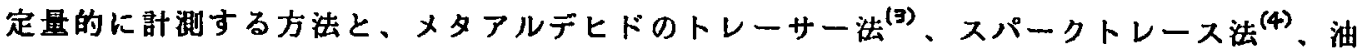
膜法 (油点法) $)^{(5)(6)}$ 等による可视化方法があり、多くの研究が行なわれてきている。

本研究では、高速直射ディーぜルエンジンの

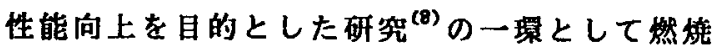
Table 1 SPECIFICATIONS OF TEST SINGLE-CYLINDER ENGINE

室内のマク口的な空気流動を比較的容易に可視 化できる油点法を用い、特に然暗室のキャビテ 1（凹み）部分の空気流動に及ぼす各種のパラ メーターの影繁を媩べ、全体の流れを予澌する ことを試みた。

本報告では、その可視化した結果と、単気简 エンジンに応用し、然焼改善試駼を行なった例 を紹介する。

$\begin{array}{lrr}\text { Bore } \quad(\mathrm{mm}) & 135 \\ \text { Stroke } \quad(\mathrm{mm}) & 140 \\ \text { Compression ratio } & 16.8 \\ \text { Injection pump type } & \text { Bosch P } \\ \text { Plunger diameter }(\mathrm{mm}) & 12.0 \\ \text { Swirl ratio } & (2.6)\end{array}$

- Mitsubishi Motors Corporation : 21-1,Simomaruko 4 Chome, Ohtaku, Tokyo

* Mitsubishi Heavy Industries, Ltd.:1-1 Akunouramachi , Nagasaki - City 


\section{2. 試験装固および試験の方法}

試験に供試した単気简エンジンの諸元を表 1 に示す。このエンジンはトラック・バス 等の、大型自動車用の直射式ディーゼルエンジンを単気简化したものである。

試倹の方法は次に示す通りである。 まず、ピストンの頂面およびキャビティ内の壁面 に光明丹を混合したシリコーン油を点状（以下 油点と呼ぶ）に冷付する。次に、シ リンダヘッドを技撯し、エンジンを所定の回㶿速度でモータリングを行なった後、ヘッド を開け、油点の流動パターンを $35 \mathrm{~m} \mathrm{~m}$ のスティールカメラで振影した。

この方法を採用するにあたり、可 視化された流動パターンが、エンジ

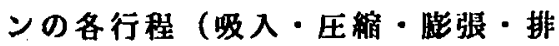
気）の、どの時点の流動を表わして いるか、が疑問になる。そこで筆 者らは、然烧室内の空気の流動を可 視化するため、図 1 に示す蜮驗装固 で、透明なピストンのキャビティの 底面にタフト(綿糸) を付け、エン ジンをモータリングしてタフトの動 きを高速度カメラで撮影した。可 视化した結果、キャビティ内のタフ トは、スワールとスキッシュ流（押 し込み流）から成ると思われる流れ

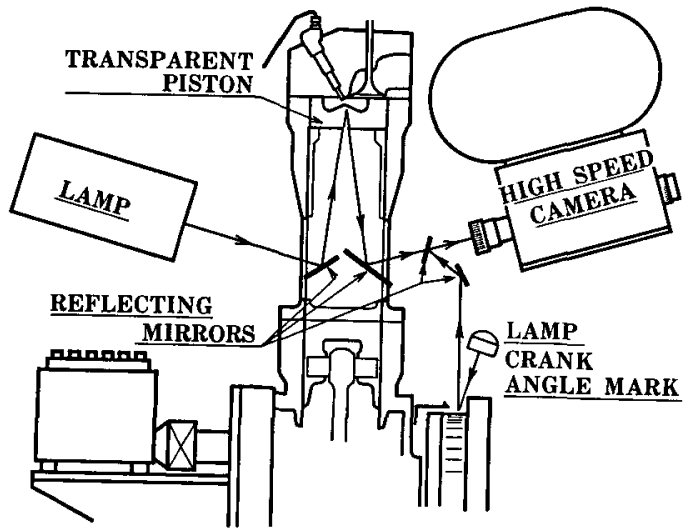

FIG.1 TEST ENGINE FOR HIGH-SPEED PHOTOGRAPHY

に流され、あたかも、䂝で波に漂う
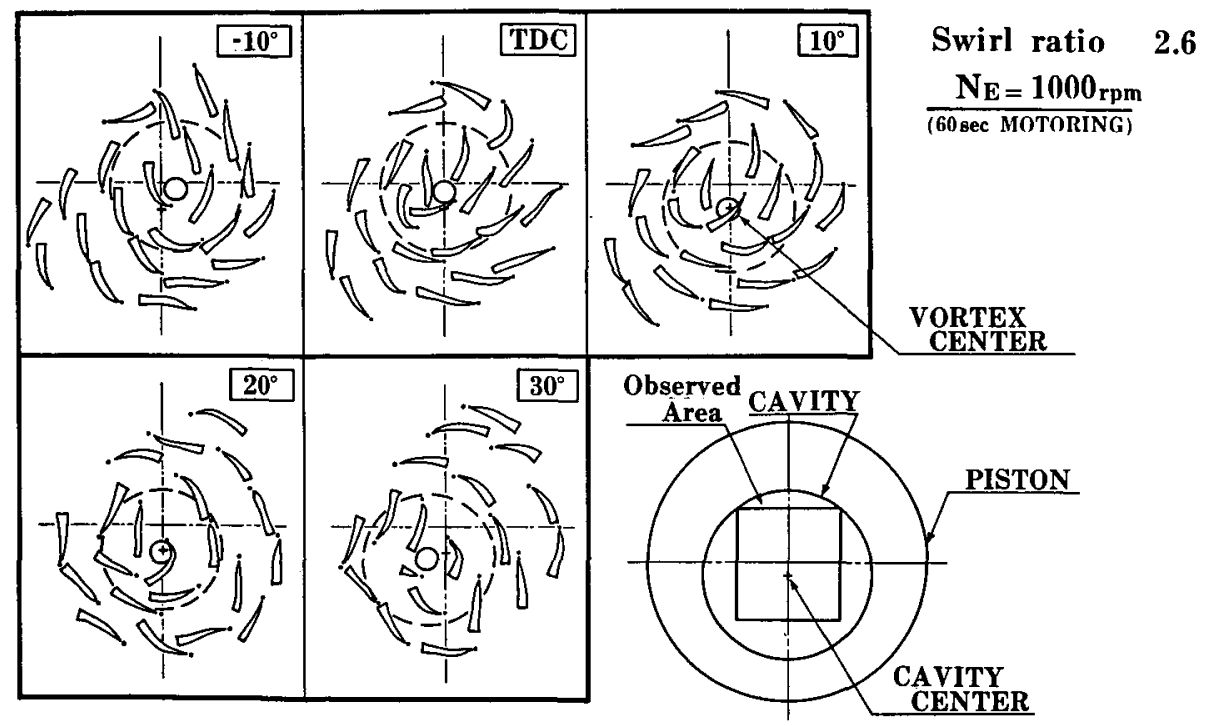

FIG.2 OBSERVATION OF AIR FLOW IN THE CAVITY BY TUFT TECHNIQUE 
海草の様な動きをしている事が钼察された。

図 2 に、压縮上死点近くにおけるタフトのスケッチ を示す。渦の中心の位置の動きに着目すると、その位 直はそれぞれのクランク角度で移動している事が判る。

この仕様と同じ仕様で、油点法により可視化した例 を図 3 に示す。この場合、渦の中心はキャビティの中 心の位置にある流動パターンとなる。これは図 2 で、 クランク角度が上死点後 $10^{\circ} 、 20^{\circ}$ でのタフトの パターンとほほ対応している。従って、油点法によ り可視化されるキャビティ内の空気流動パターンは、 压縮上死点直後の流九を表していると推定される。

次に、試騟条件について検討した。测付した油点 の移動する量は、空気の速度と試験時間に大きく影響

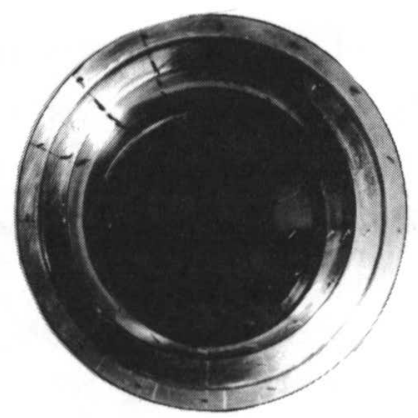

$$
\begin{aligned}
& \text { Swirl ratio } 2.6 \\
& \frac{\mathrm{NE}_{\mathrm{E}}=1000_{\mathrm{rpm}}}{(60 \mathrm{sec} \text { MOTORING })}
\end{aligned}
$$

FIG.3 VISUALIZATION OF AIR FLOW BY OIL DOT METHOD (TRANSPARENT PISTON) を受けるので、スワール比、エンジン回転速度、およ び運転時間を変えその影響度を調べた。図4にその結果の例をに示す。これらの図か ら流線が重ならないで、流線の形状と流れの方向を明暸に锶察できるエンジンの回転速 度 $1000 \mathrm{rpm}$ 、モータリング時間 60 秒間を本試験の槽準条件とした。

\section{3 . 試験結果}

\section{1 スワール比の影響（図 4 ）}

スワール比は エンジンの回転速度に対するシリンダ内に吸入された空気の旋回速度の 比で定義され、定常流試験で得られる値である(7) スワール比に対応する油点の移動量を 調查すると、図4の様になり、生産エンジンの敕準のスワール比 2.6 では、キャビティ

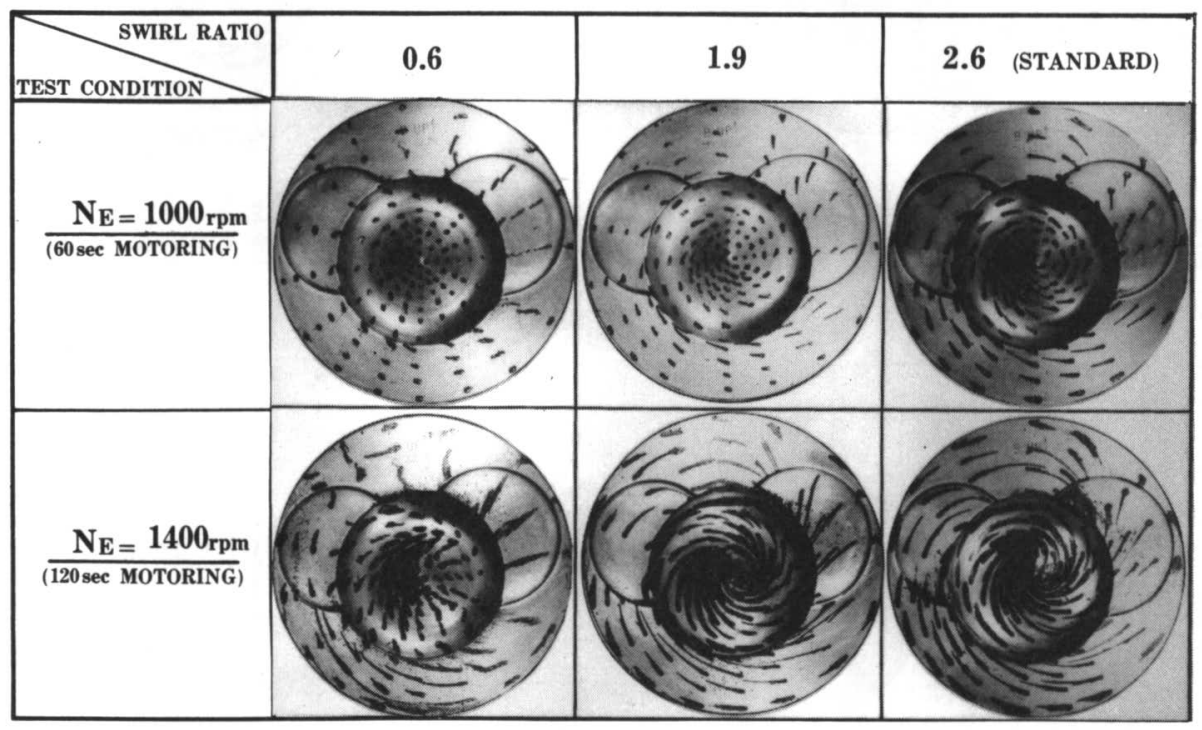

FIG.4 INFLUENCE OF SWIRL RATIO ON STREAK LINES 
のオフセット㑡に強く旋回する流れがあり、渦の中心はシリンダ中心の近くにある。ス ワール比を 1.9 にすると、渦の中心はシリンダ中心より少し右に寄る。更に小さく 0.6 にすると、流動パターンは上記のケースとは異なり、キャビティ内の左側の部分は旋 回する流れ、右側はキャビティ中心に向かう流れとなっており吸気過程の影響が残ってい ることを示している。

3.2 キャビティの位直の影響 （図 5、6）

吸気過程で 吸気ポートから流入する流れの効果を調べるため、キャビティの位置を変 更してその影響を調べた。図 5 にその結果を示す。吸気ポートの入口はそれぞれのピ ストンの右上にあり、空気は図の右側の吸気弁から吸入される。タイプ（1)の供試ピ ストンはキャビティの位直が吸気ポート入口と反対側に、タイプ (2) では吸気ポート入口 側に、それぞれオフセットして配固されている。 また タイプ (3) - (5) は、キャビテ ィ位直による流動の変化を確認するために、特に、選定したものである。

タイプ(1) では渦の中心はシリンダ中心の近くにある。タイプ 2 ではキャビティの 中心に渦の中心がある。 また全部のタイプに亘り共通して、キャビティの左下側に速い 流れが鼣察される。

このキャビティ内での流速分布の偏りは次の様に説明できる。吸気行程の終りには、 空気の流動パターンは図 6 に示す様に、スワール（旋回流）と、ピストンの下降によって 生じたシリンダー軸方向の流れが、合成された流れになっていると推定される。シリンダ

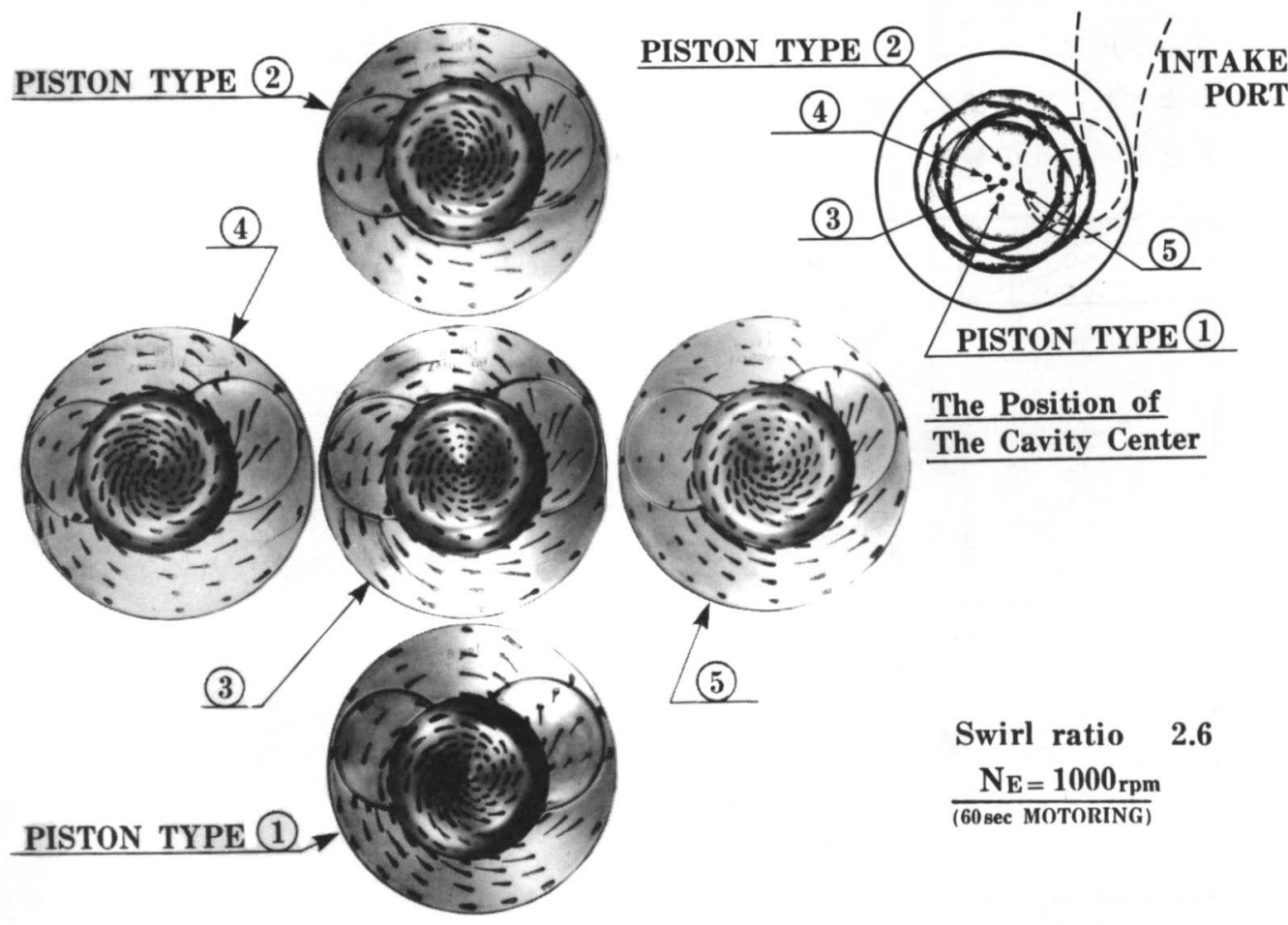

FIG.5 EFFECT OF CAVITY POSITION ON AIR FLOW PATTERNS 
軸方向の成分は、ピストン の上昇に従って旋回成分に 変哇されるとされているが(日) これらの可視化した結果は。 上死点後にも、この軸方向 の成分が残っており、その 為にキャビティ内の速度分 布に偏りが生じたものと推 定される。

以下の試験では、ピスト ンタイプ(1)で、各パラメ ーターの影郘を調べた。

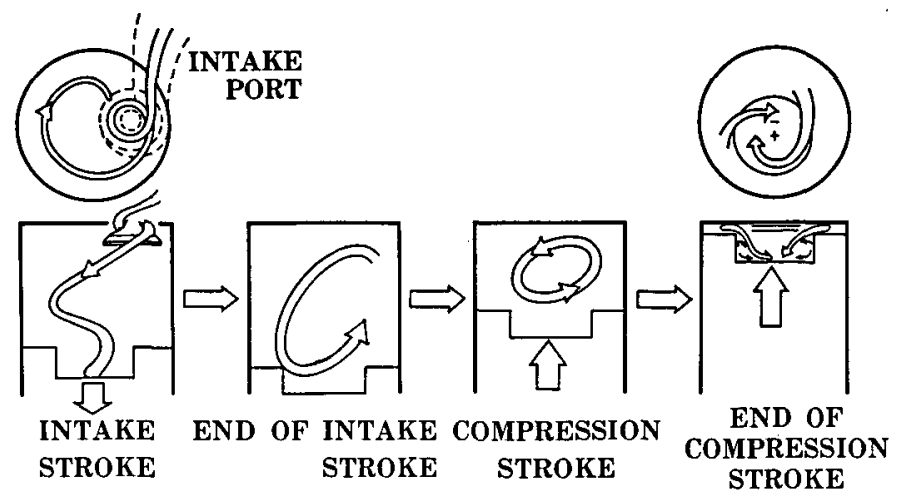

3.3キャビティのオフセット量の影变（図 7)

スワール此とキャビティの径を一定にしてシリンダ中心に対するキャビティのオフセッ 卜量曰を変化させた。オフセット量が小さい時には、滴の中心はシリンダ中にあり 、オフセット量が大きい湯合、キャビティの右上にある。これは、キャビティの左下側 にシリンダ中心方向の成分が強く残っているためであり、㢼の中心はキャビティの右上㑡 に移動していると推定される。

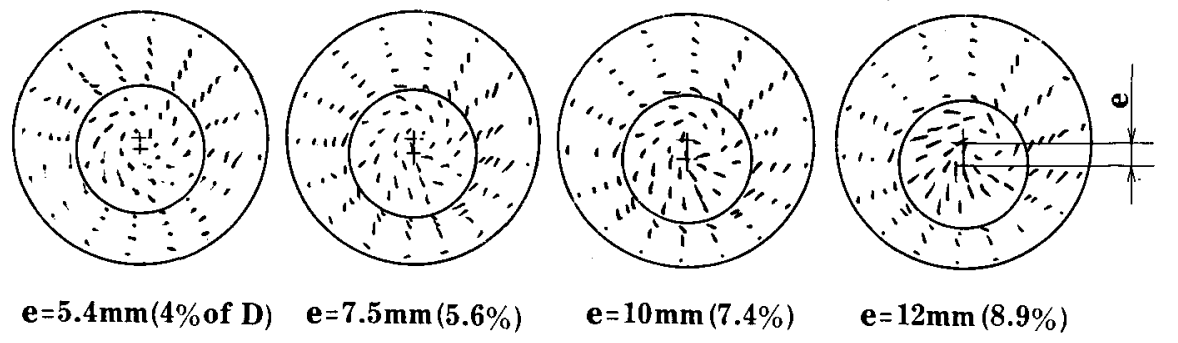

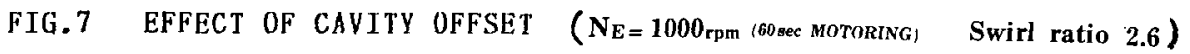

3.4キャビティの径の影辝（図 8 ）

キャビティのオフセット量を一定にして、キャビティの径 d c を変更した。その結 果、キャビティの径が大きい程、径の自乘に反比例してスワール速度は遅い。(8)また渦の 中心は、キャビティの径が大き い時には、キャビティの中心に あり、径が小さくなるに従い、 キャビティの中心に対してシリ ンダ中心の対㑡に移る䫏向に ある。

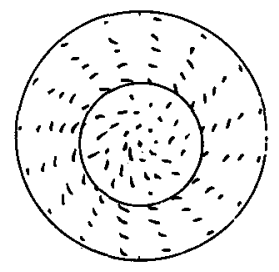

de $/ D=48 \%$

FIG.8 EFFECT OF CAVITY DIAMETER $-17-$

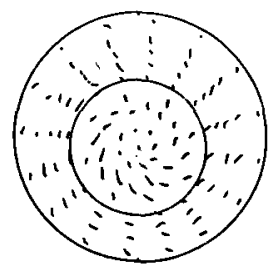

$\mathbf{5 2} \%$

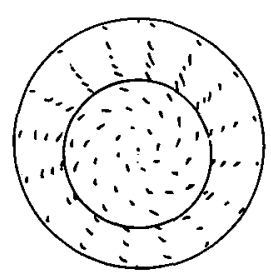

$59 \%$

Swirl ratio 2.6 $\frac{\mathrm{Ne}=1000_{\mathrm{rpm}}}{(\text { fó aec MOTORING) }}$ 
4. エンジンの然焼改善への適用

上記の铸祭粘果からキャビティ内の空気流動には多 くの場合、速度の分布に偏りがあることが明らかにな った。扯って、然媇を改善するには、キャビティ内 の然料の分散を考虑したチューニングが必要である。

そこで、図9に示す様に、キャビティとノスルの噴 射方向をパラメーターとして変化させ、燃㜔チューニ ング試験を実施した。その粘果 图 10 に示す様に、 キャビティの径に対底して、然娭（排煙惯度、平均有 効圧力）が最良となるノスルの噴射方向がある。最 良の仕様では、排ガス対策前の生産仕様（ d c $=75$, Nozzle Type A）に比輘して、58 年排ガス規制を嗾 足させ、同じ然料噴射量で、平均有効压力が約 $3 \%$ 改 善された。(8)

5. むすび

油点法を使用して、エンジン の然媇室のキャビティ内の空気 の流れを、パラメータスタディ によりマクロ的に把握でき、そ
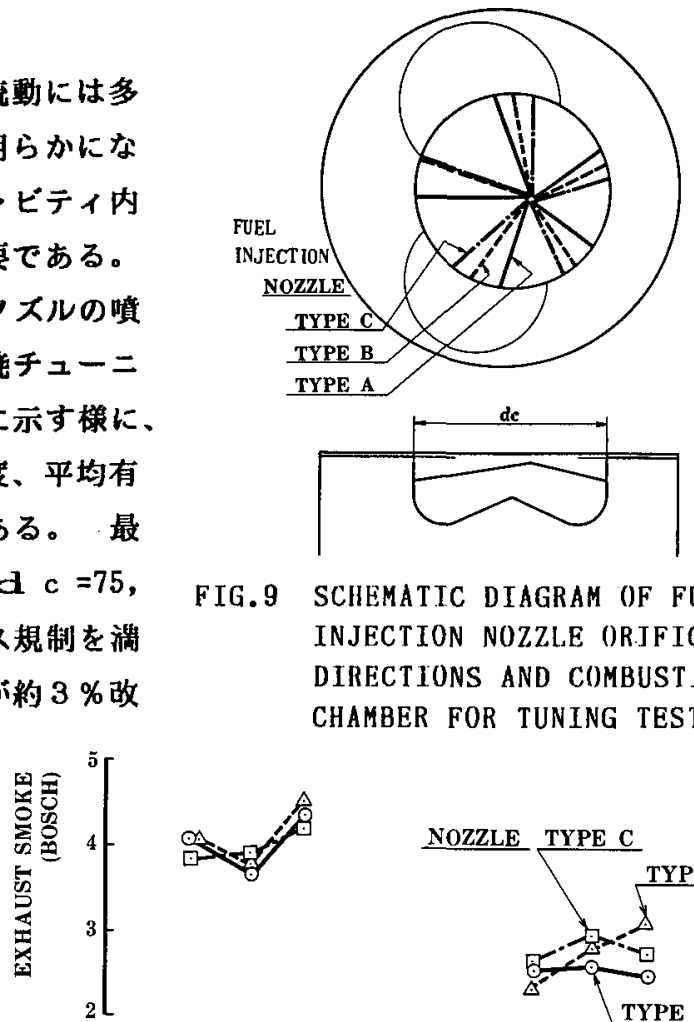

FIG. 9 SCHEMATIC DIAGRAM OF FUEL INJECTION NOZZLE OR.JFICE DIRECTIONS AND COMBUSTION CHAMBER FOR TUNING TESTS

の結果を燃娔改善に結びつける 事ができた。今後、この結果 をもとに空気の流れを定量的に 把㩧し、更に数值シミュレーシ ヨンにより一般化して、他の機 種に応用できる様にして行きた
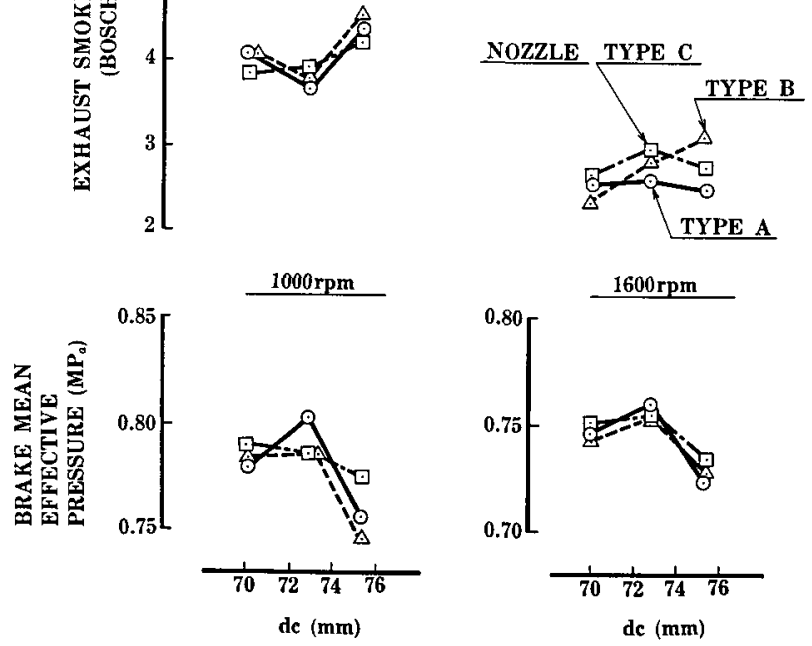

FIG.10 EFFECTS OF NOZZLE ORIFICE DIRECTIONS AND CAITY DIAMETER FOR DIESEL ENGINE COMBUSTION TUNING

6. 参考文献

（1）例えは F.Brandl,et al。, SAE PAPER 790040

（2）例えは 神本 武征 他 4名，内然機関合同シンポジウム 59-1, P.25

（3）井元 浩二, 内然機関 V。I，1 3 N。.146(74-1)，P.11

(4) K.Komiyama,et al., S A E PAPER 800967

（5）浜本 募輔，第 4 回流九の可視化シンポジウム1976.6.15-16,P.1

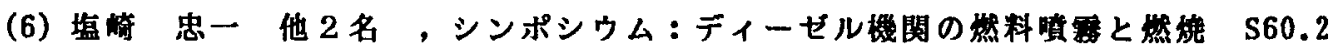

(7) F.Pischnger, A T Z J J . 65, N r $1(1963-1), P .11-16$

(8) 例えは K.Kanairo,et al, ,COMOD I A' 85 TOKYO 1985 , 9, P.373 